\title{
BMS-345541 inhibits airway inflammation and epithelial-mesenchymal transition in airway remodeling of asthmatic mice
}

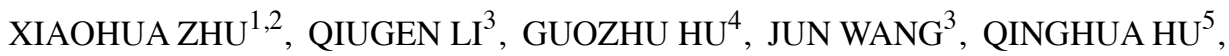 \\ ZHIQIANG LIU $^{6}$, GANG WU ${ }^{1}$ and YING $\mathrm{ZHONG}^{1}$ \\ ${ }^{1}$ Graduate School, Nanchang University; ${ }^{2}$ Respiratory Department, Jiangxi Children's Hospital; \\ ${ }^{3}$ Respiratory Department and ${ }^{4}$ Central Laboratory, Jiangxi People's Hospital; ${ }^{5}$ Central Laboratory and \\ ${ }^{6}$ Clinical Laboratory, Jiangxi Children's Hospital, Nanchang, Jiangxi 330006, P.R. China
}

Received February 1, 2018; Accepted June 28, 2018

DOI: $10.3892 / \mathrm{ijmm} .2018 .3762$

\begin{abstract}
The present study aimed to investigate the possible effects and regulatory mechanism of the inhibitor of nuclear factor- $\kappa \mathrm{B}$ kinase complex $\beta$ subunit $(\mathrm{IKK} \beta$ ) inhibitor BMS-345541 on airway inflammation, airway remodeling and epithelial-mesenchymal transition (EMT) in an ovalbumin (OVA) exposure asthma model in mice. The asthma mouse model was generated by sensitization and challenge with OVA. BMS-345541/dimethyl sulfoxide (DMSO) was administered perorally dairy in two therapeutic groups throughout the entire OVA challenge process. At $24 \mathrm{~h}$ following the last challenge, airway hyperresponsiveness (AHR) and airway inflammation were examined, and serum, bronchoalveolar lavage fluid (BALF) and lung samples were collected. Lung tissue was stained and assessed for pathological changes. The total number and classification of inflammatory cells in the BALF were examined. Levels of transforming growth factor $\beta 1$ (TGF 1 1) in the serum and BALF were measured using an enzyme-linked immunosorbent assay. The differential expression of EMT regulators E-cadherin and vimentin was detected by immunohistochemical staining, reverse transcriptionquantitative polymerase chain reaction analysis and western blot analysis. The results showed that OVA successfully induced allergic asthma. The asthmatic mice had AHR, airway inflammation, airway remodeling, a high expression of TGF $\beta 1$, and evidence of EMT. Following BMS-345541 treatment, there was significant inhibition of pathophysiological signs, including increased pulmonary eosinophilia infiltration, mucus hypersecretion and AHR. Treatment with
\end{abstract}

Correspondence to: Dr Qiugen Li, Respiratory Department, Jiangxi People's Hospital, 92 Aiguo Road, Nanchang, Jiangxi 330006, P.R. China

E-mail: nclqg2017@163.com

Key words: BMS-345541, epithelial-mesenchymal transition, airway remodeling, airway inflammation, asthma
BMS-345541 significantly reduced levels of TGF $\beta 1$. In addition, BMS-345541 notably downregulated the expression of vimentin and increased the expression of E-cadherin. These data suggested that the increased secretion of TGF $\beta 1$ induced by asthmatic inflammation can lead to EMT, and the IKK $\beta$ inhibitor BMS-345541 may alter airway remodeling by preventing EMT in an OVA asthma model. Therefore, IKK $\beta$ inhibitors require investigation as potential asthma therapies.

\section{Introduction}

Asthma is a common disease that is characterized by reversible airflow obstruction, airway hyperresponsiveness (AHR), airway inflammation, airway remodeling, mucus hypersecretion and subepithelial fibrosis $(1,2)$. It is a heterogeneous syndrome affected by several factors, including the environment, genetic background, and infection (3). Multiple cell types and cellular components are known to be involved in the pathophysiological processes of asthma. One important link in the pathogenesis of asthma is airway remodeling caused by recurrent injury and repair processes initiated by chronic inflammation (4). Changes in the morphology and function of airway epithelial cells are key to airway remodeling. This remodeling is considered to be the pathological basis for irreversible AHR and airway obstruction (5). During airway remodeling the number of goblet cells increases, resulting in increased mucus secretion, which can cause airway obstruction and lead to asthma-related mortality.

Repeated chronic inflammation in the asthmatic airway induces epithelial cells to transdifferentiate into myofibroblasts. This is an example of epithelial-mesenchymal transition (EMT). EMT may be involved in the process of airway remodeling and subepithelial fibrosis in asthma (6) and may be a possible mechanism of airway inflammation (7). Persistent EMT causes detrimental changes in pulmonary function (8). Furthermore, EMT decreases the sensitivity of airway epithelial cells to drug treatments and thus decreases the therapeutic efficacy of glucocorticoids in patients with severe asthma (9). Abnormal EMT is now considered to be the central event in asthma pathophysiology (10). EMT is a 
current focus of investigations of the mechanisms underlying airway remodeling in asthma. A variety of proteins are important in EMT, including E-cadherin and vimentin, which represent epithelial and mesothelial features, respectively. The decreased expression of E-cadherin, the increased expression of vimentin, and the transition from epithelial to mesenchymal cell morphology are important manifestations of the EMT process. However, the molecular mechanisms underlying these effects remain to be fully elucidated. No effective treatments for asthma-related airway remodeling are available (11).

Transforming growth factor $\beta 1$ (TGF $\beta 1$ ) is an important cytokine involved in airway remodeling that mediates tissue inflammation in asthma. The mechanisms underlying the effects of TGF $\beta 1$ on asthma remain to be fully elucidated. Therefore, it is hypothesized that TGF $\beta 1$-induced EMT may be involved in the processes of airway inflammation and airway remodeling. Nuclear factor- $\kappa \mathrm{B}(\mathrm{NF}-\kappa \mathrm{B})$ is an important transcriptional factor in EMT and in the epithelial cell inflammation of asthma (9). TGF $\beta$-induced EMT is driven by $\mathrm{NF}-\kappa \mathrm{B}-$ dependent cell signaling (12). The persistent activation of $N F-\kappa B$ has been observed in allergic airway inflammation (13). Therefore, $\mathrm{NF}-\kappa \mathrm{B}$ has emerged as a vital therapeutic molecular target, and the inhibition of $N F-\kappa B$ activity may offer potential as a method to manage asthma.

Several factors are involved in regulating the expression and activity of NF- $\kappa \mathrm{B}$, providing several targets for the pharmacological inhibition of $\mathrm{NF}-\kappa \mathrm{B}$. One inhibitor target is inhibitor of $\mathrm{NF}-\kappa \mathrm{B}(\mathrm{I} \kappa \mathrm{B})$ kinase (IKK), a kinase complex that phosphorylates $\mathrm{I} \kappa \mathrm{B}$, the inhibitory subunit of the $\mathrm{NF}-\kappa \mathrm{B}$ complex, thereby releasing $\mathrm{I} \kappa \mathrm{B}$ and activating $\mathrm{NF}-\kappa \mathrm{B}$. The IKK/NF- $\kappa \mathrm{B}$ pathway is important in regulating inflammation. IKK $\beta$ is particularly important as a major upstream regulator of $\mathrm{NF}-\kappa \mathrm{B}$ activity, with an important role in the immune response and inflammatory reactions (14). Inhibitors of IKK $\beta$, including BMS-345541 [(2'-aminoethyl)amino-1,8-dimethy limidazo(1,2-a) quinoxaline], have certain pharmacokinetic characteristics, including $100 \%$ oral bioavailability and an intravenous half-life of $2.2 \mathrm{~h}$, which makes them particularly well suited for use in investigating the utility of IKK inhibitors in disease models (15). In various cell and animal models of several diseases, BMS-345541 is key in EMT and suppresses inflammatory responses by inhibiting the activation of NF- $\mathrm{B}$ (16-18). These results indicate that BMS-345541 may have potent anti-inflammatory activity in the context of asthma. However, whether BMS-345541 can be used to inhibit asthma-induced airway inflammation, airway remodeling and the EMT observed in asthma, and the exact therapeutic mechanisms of BMS-345541 in asthma treatment remain to be fully elucidated.

Therefore, to provide novel ideas and methods for the clinical treatment of asthma and to investigate the mechanisms of asthma, it was hypothesized that the secretion of TGF $\beta 1$ may result in EMT, and the role of BMS-345541 on airway inflammation, airway remodeling and potentially in the regulation of EMT marker protein expression were investigated in an ovalbumin (OVA)-induced asthma model in mice. If BMS-345541 inhibits asthma phenotypes in the OVA mouse model, as expected, it is likely to be an important tool in the elucidation of the roles of TGF $\beta 1$, EMT and NF- $\kappa \mathrm{B}$ in asthma pathophysiology and in the identification of targets for novel drug therapies.

\section{Materials and methods}

Animals. A total of 32 female BALB/c mice aged 6-8 weeks and weighing $25 \pm 3 \mathrm{~g}$ were maintained in the Laboratory Animal Science Centre of Nanchang University (Nanchang, China). All the mice were housed under specific pathogen-free laboratory conditions in a $12 \mathrm{~h}$ light/dark cycle at a temperature of $20 \pm 5^{\circ} \mathrm{C}$ with $50 \pm 10 \%$ humidity. Mice had ad libitum access to food and water. Care was taken to alleviate any pain and suffering of the mice. All experiments were performed according to institutional regulations, and all procedures performed in the present study were approved by the Ethics Commission of Jiangxi People's Hospital (Nanchang, China).

Reagents. The reagents used were as follows: OVA (Sigma-Aldrich; Merck KGaA, Darmstadt, Germany), acetylcholine chloride (Ach; Sigma-Aldrich; Merck KGaA), phosphate-buffered saline (PBS; Sigma-Aldrich; Merck KGaA), sodium pentobarbital (Sinopharm Chemical Reagent Co., Ltd., Shanghai, China), BMS-345541 (Abcam, Cambridge, MA, USA), E-cadherin antibody (cat. no. ab76055; Abcam), vimentin antibody (cat. no. ab92547, Abcam), $\beta$-actin antibody (cat. no. ab179467; Abcam), glyceraldehyde 3-phosphate dehydrogenase (GADPH; Sigma-Aldrich; Merck KGaA), dimethyl sulfoxide (DMSO; Sigma-Aldrich; Merck KGaA), diaminobenzidine (DAB; Santa Cruz Biotechnology, Inc., Dallas, TX, USA), an enzyme-linked immunosorbent assay (ELISA) kit (Bio-Rad Laboratories, Inc., Hercules, CA, USA), Pierce Enhanced Chemiluminescence (ECL) western blot substrate (Thermo Fisher Scientific, Inc., Waltham, MA, USA), a reverse transcription kit (Promega Corporation, Madison, WI, USA), a quantitative polymerase chain reaction (qPCR) kit (TransStart Green; Beijing Transgen Biotech Co., Ltd., Beijing, China), a bicinchoninic acid (BCA) protein assay kit and radioimmunoprecipitation assay (RIPA) lysis buffer (Beijing ComWin Biotech Co., Ltd., Beijing, China). The qPCR primers were designed and synthesized by Nanjing Kingsy Biotechnology (Nanjing, China).

Asthma sensitization, challenge and treatment protocol. The 32 mice were divided into four groups of eight mice: Control, OVA, OVA + DMSO, and OVA + BMS-345541 groups. First, eight mice were randomly selected from the 32 mice as the normal control group. The remaining 24 mice were then selected to be sensitized and challenged with OVA. The mice were sensitized with intraperitoneal (i.p.) injections of $10 \mu \mathrm{g}$ of OVA emulsified in aluminium hydroxide in a total volume of $0.2 \mathrm{ml}$ on days 0,7 and 14. Between days 21 and 28, they were challenged by aerosol exposure to 5\% OVA for 30 min daily for 7 days. The control group mice were treated with PBS for sensitization and stimulation using the same protocol.

Prior to OVA challenge, the 24 sensitized mice were equally divided into three groups of eight mice: OVA group, OVA + DMSO group and OVA + BMS-345541 group. The OVA + BMS-345541 group comprised mice treated with BMS-345541. The BMS-345541 was dissolved in 1\% DMSO, and the resulting solution was diluted with sterile water to a final concentration of $10 \mu \mathrm{g} / \mu \mathrm{l}$. The OVA + DMSO group was the DMSO vehicle control group. BMS-345541 $(50 \mathrm{mg} / \mathrm{kg})$ 


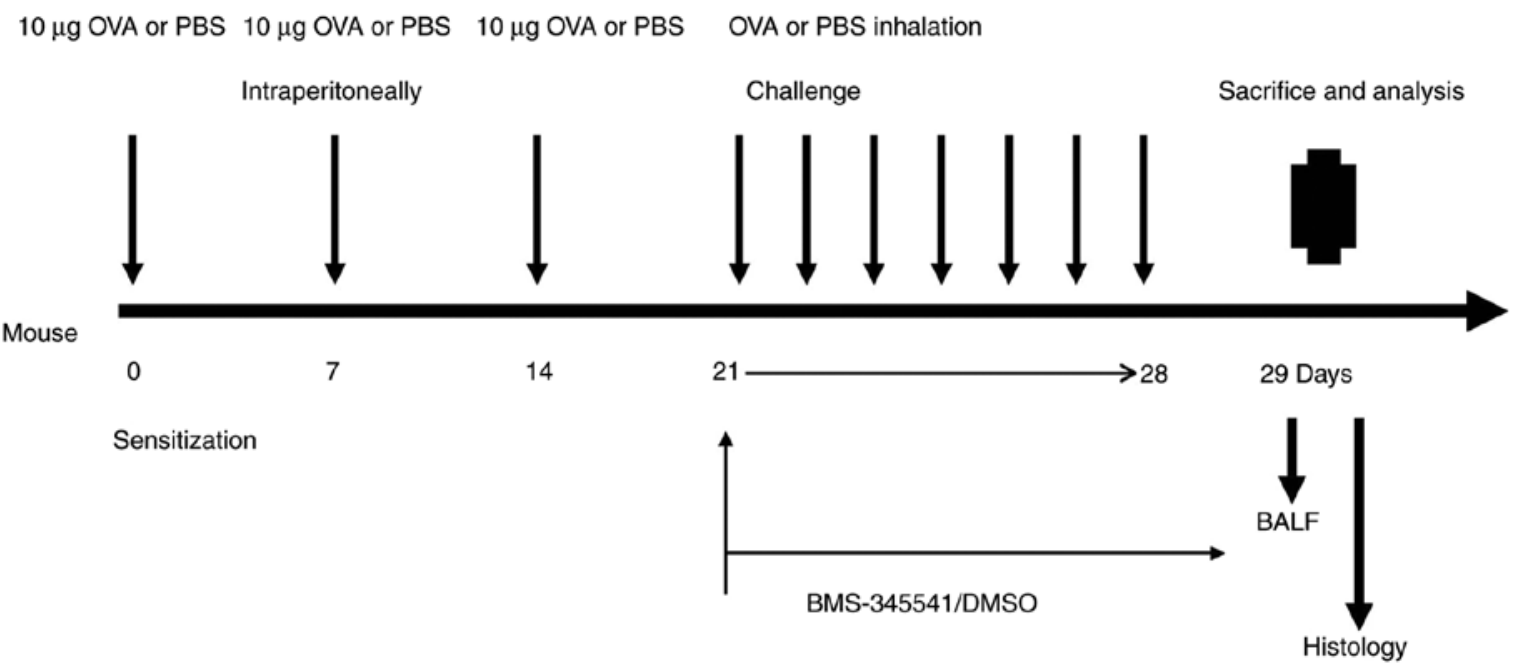

Adaptive asthma protocal

Figure 1. Experimental design for the OVA-induced asthma model. Mice were sensitized with intraperitoneal injections of $10 \mu \mathrm{g}$ of OVA emulsified in aluminium hydroxide in a total volume of $0.5 \mathrm{ml}$ on days 0,7 and 14 , followed by seven consecutive challenges each day by exposure to OVA aerosol for $30 \mathrm{~min}$. Prior to daily OVA nebulization challenge, BMS-345541 or DMSO were administered in the BMS-345541- or DMSO-treated groups, respectively. The control mice were treated with PBS for the sensitization and stimulation. Mice were sacrificed $24 \mathrm{~h}$ following the final challenge. BALF samples were collected and the lungs were dissected for analysis. OVA, ovalbumin; BALF, bronchoalveolar lavage fluid; PBS, phosphate-buffered saline; DMSO, dimethyl sulfoxide.

or vehicle $(20 \mu 1$ DMSO in a total of $200 \mu l$ saline, without BMS-345541) was administered to the mice by oral gavage using a feeding needle (18 gauge, $5 \mathrm{~cm}$ ) for 7 days (19). No such intervention was performed in the OVA group mice. The detailed experimental protocol is shown in Fig. 1.

Evaluation of asthma symptom severity, and measurement of airway responsiveness. A symptom assessment of asthma in mice was performed with regard to specific criteria, as previously described (20). The asthma symptoms were observed in $15 \mathrm{~min}$ during inhaled OVA. Airway responsiveness to Ach was measured with a whole-body and invasive plethysmography (Buxco Electronics, Inc., Troy, NY, USA) and analyzed as previously described (21). Lung resistance (RL) was measured to assess the change in AHR. At $24 \mathrm{~h}$ following the final challenge, all mice were weighed and anesthetized with $2 \%$ sodium pentobarbital $(30 \mathrm{mg} / \mathrm{kg})$ via i.p. injection. The cervical trachea was completely exposed by blunt dissection, a tracheal tube (2-mm internal diameter) was inserted into the trachea via a tracheotomy. The mice were then placed into the whole-body plethysmography chamber, and the tracheal tube was connected to the ventilator for mechanical ventilation with a tidal volume of $0.2 \mathrm{ml}$ and a frequency of 140 breaths $/ \mathrm{min}$. After $5 \mathrm{~min}$ of equilibration on the ventilator, PBS and a series of increasing doses of Ach $(3.125,6.25,12.5$ and $25 \mathrm{mg} / \mathrm{ml})$ were administered through the ventilator with an ultrasonic nebulizer. The data were collected through the sensor.

Serum, bronchoalveolar lavage fluid (BALF) and lung tissue specimen preparation. The mice were sacrificed, following which one side of the bronchus was ligated and the airway on other side was lavaged three times with $0.5 \mathrm{ml}$ of normal saline; $80 \%$ of the input volume was recovered. BALF was centrifuged at $500 \mathrm{x} \mathrm{g}$ for $10 \mathrm{~min}$ at $4^{\circ} \mathrm{C}$. The total number of cells in the BALF was counted with a hemocytometer, and the percentages of the inflammatory cells were determined by counting 400 cells in randomly selected areas of the slide under a light microscope. All counts were performed in a blinded manner and in a randomized order by the same observer at the end of the experiment. The BALF supernatants were stored at $-80^{\circ} \mathrm{C}$ for ELISA assessment.

Following the collection of BALF, all mice underwent an abdominal surgical procedure in which the abdominal anatomy was carefully examined to identify and expose the inferior vena cava, from which $0.5-1 \mathrm{ml}$ of venous blood was withdrawn into a sterile Eppendorf tube. Following standing for $1 \mathrm{~h}$, the sample was centrifuged at $1,000 \mathrm{xg}$ at $4^{\circ} \mathrm{C}$ for $10 \mathrm{~min}$, and the supernatant was stored at $-80^{\circ} \mathrm{C}$ for further analysis.

The non-lavaged side of the lungs was harvested, the lower lobe was isolated, and fixed in $0.1 \mathrm{mmol} / 1$ paraformaldehyde, and was made into $4-\mu \mathrm{m}$ thick paraffin-embedded tissue sections for histopathological analysis via immunohistochemistry. The upper and middle lobes were stored at $-80^{\circ} \mathrm{C}$ in a refrigerator for reverse transcription-qPCR (RT-qPCR) and western blot analyses.

ELISA for TGF $\beta 1$ in serum and BALF. The concentrations of TGF $\beta 1$ in the serum and BALF were measured with an ELISA kit according to the manufacturer's protocol. A microplate reader was used to detect the optical density (OD) for the ELISA. TGF $\beta 1$ levels were determined by the OD values.

Lung tissue histopathology. The paraffin-embedded sections were stained with hematoxylin and eosin (H\&E) to observe changes in airway inflammation and airway remodeling. Periodic acid-Schiff (PAS) staining was performed to evaluate airway goblet cell hyperplasia and mucus production. The stained sections were mounted on slides and examined under a light microscope (Olympus BX50, Olympus, Tokyo, Japan). Images were captured with a Nikon DS-Ri2 digital camera. 
Table I. Primers and sequences.

\begin{tabular}{|c|c|c|}
\hline Name & Sequence $\left(5^{\prime}-3^{\prime}\right)$ & $\begin{array}{c}\text { Fragment } \\
\text { length } \\
\text { (bp) }\end{array}$ \\
\hline \multirow[t]{2}{*}{ E-cadherin } & F: AAAAGAAGGCTGTCCTTGGC & 106 \\
\hline & R: GAGGTCTACACCTTCCCGGT & \\
\hline \multirow[t]{2}{*}{ Vimentin } & F: TCCACTTTCCGTTCAAGGTC & 91 \\
\hline & R: AGAGAGAGGAAGCCGAAAGC & \\
\hline \multirow[t]{2}{*}{ GAPDH } & F: ATGGAGGGGAATACAGCCC & \\
\hline & R: TTCTTTGCAGCTCCTTCGTT & 149 \\
\hline
\end{tabular}

F, forward; R, reverse.

Epithelial thickness, the area between the luminal cell membrane and the basement membrane, was measured at four sites in five different medium-sized bronchi per slide using Image Pro Plus 6.0 image analysis software (Media Cybernetics, Inc., Rockville, MD, USA). All the measurements are provided as the average epithelial thickness per group.

Immunohistochemical analysis of the expression of E-cadherin and vimentin in lung tissues. The sections of lung tissues were deparaffinized in xylene and rehydrated in graduated ethanol solutions. Following microwave-based antigen retrieval with citric acid pretreatment, the sections were incubated in $1 \%$ hydrogen peroxide for $15 \mathrm{~min}$ to block endogenous peroxidase. Subsequently, the specimens were incubated with a mouse polyclonal antibody to E-cadherin (1:200) or a rabbit polyclonal antibody to vimentin (1:200) at $4^{\circ} \mathrm{C}$ overnight, respectively. The sections were then incubated with anti-mouse (cat. no. CW01025) or anti-rabbit (cat. no. CW01035) horseradish peroxidase (HRP)-conjugated secondary antibody (1:100; Beijing Com Win Biotech Co., Ltd.) for $30 \mathrm{~min}$ at room temperature, followed by staining with DAB (22). For the negative control, the primary antibody was replaced with PBS. The sections were observed under a light microscope (magnification, x400). E-cadherin was mainly expressed in the cell membrane and cytoplasm, whereas vimentin was mainly expressed in the cytoplasm. The brown staining of a cell membrane or cytoplasm is a positive signal in protein immunohistochemistry. The mean integrated OD (IOD) was then detected using the Image Pro Plus 6.0 image analysis system for all the sections. The IOD value represented the expression of each protein. The mean IOD values of each group were compared.

$R T$-qPCR analysis of E-cadherin and vimentin expression. Total RNA was extracted from the lung tissues using TRIzol. The mRNA was then reverse transcribed using a reverse transcription kit, according to the manufacturer's protocol. The reaction system was made up to $20 \mu 1$ with RNAse free water and contained $2.5 \mathrm{mM} \mathrm{MgCl}_{2}(4 \mu \mathrm{l})$, reverse transcription 10X buffer $(2 \mu \mathrm{l}), 0.5 \mathrm{mg} / \mathrm{ml}$ primers $(1 \mu \mathrm{l})$, dNTP mix $(2 \mu \mathrm{l})$ and AMV reverse transcriptase $(0.7 \mu \mathrm{l})$. The $\mathrm{RT}$ reaction occurred at $42^{\circ} \mathrm{C}$ for $1 \mathrm{~h}$ and was subsequently inactivated at $95^{\circ} \mathrm{C}$ for 5 min. A qPCR kit was used to amplify the resulting cDNAs, and fluorescence was detected with an 7500 PCR detection system (Applied Biosystems; Thermo Fisher Scientific, Inc.). The PCR reaction system was made up to $20 \mu \mathrm{l}$ with RNAse free water and contained 2X TransStart Green qPCR Super MIX UDG $(10 \mu \mathrm{l}), 10 \mu \mathrm{M}$ forward primer $(0.4 \mu \mathrm{l}), 10 \mu \mathrm{M}$ reverse primer $(0.4 \mu \mathrm{l}), 50 \mathrm{X}$ passive reference dye $(0.4 \mu \mathrm{l})$ and cDNA $(1 \mu \mathrm{l})$. The thermocycling conditions were as follows: $50^{\circ} \mathrm{C}$ for $2 \mathrm{~min}, 94^{\circ} \mathrm{C}$ for $10 \mathrm{~min}$, followed by $40-45$ cycles of $94^{\circ} \mathrm{C}$ for $5 \mathrm{sec}$ and $60^{\circ} \mathrm{C}$ for $30 \mathrm{sec}$. GADPH was used as an internal control. The PCR products were subjected to melting curve analysis to ensure that a single amplification product was produced. The relative expression levels of E-cadherin and vimentin were calculated using the quantification cycle $\left(2^{-\triangle \Delta C q}\right)$ method (23). The sequences of primers used for RT-qPCR analysis are listed in Table I.

Western blot analysis of E-cadherin and vimentin expression. Total protein was extracted from lung tissues using RIPA lysis buffer. Protein concentration was determined with a BCA protein assay, following which the proteins (50 $\mu \mathrm{g} / \mathrm{lane})$ were separated on $15 \%$ SDS-PAGE gels and transferred onto PVDF membranes. The membranes were blocked with 5\% non-fat milk for $1 \mathrm{~h}$ at room temperature and then incubated with anti-E-cadherin $(1: 1,000)$ and anti-vimentin $(1: 1,000)$ antibodies overnight at $4^{\circ} \mathrm{C}$. The $\beta$-actin antibody $(1: 2,000)$ was used as an internal control. Following three washes, the membranes were probed with HRP-conjugated secondary antibodies (1:3,000 in blocking buffer) at room temperature for $2 \mathrm{~h}$ and visualized with ECL reagent. The relative expression levels of E-cadherin and vimentin were quantified using Image lab Version 6.0 software (Bio-Rad Laboratories, Inc.) and were normalized to levels of $\beta$-actin. The normalized level of expression in the control group was set to 1.00 , and the normalized expression in the OVA and OVA + BMS-345541 groups is expressed relative to the control.

Statistical analysis. All data were processed using SPSS 19.0 (IBM SPSS, Armonk, NY, USA), and all quantitative data are presented as the mean \pm standard deviation $(n=8$ mice/sample per group). The data were compared using a single-factor analysis of variance following variance determination. Comparisons among multiple groups were assessed using the Least Significant Difference method. If the variance was not homogeneous, Tamhane's multiple comparison procedure was used to assess comparisons among multiple groups. $\mathrm{P}<0.05$ was considered to indicate a statistically significant difference.

\section{Results}

Effect of BMS-345541 on OVA-induced symptoms. During OVA challenge, the OVA-group mice showed a variety of asthma-related symptoms, including dysphoria, shortness of breath and irregular breath rhythm, cyanosis, coughing, nose scratching and ear grasping, shrinking forelimb lift, and decreased activity. However, following treatment with BMS-345541, the asthmatic symptoms in the OVA + BMS-345541 group were significantly reduced, compared with those in the OVA and OVA + DMSO groups. The control group mice exhibited no asthma attack or allergic symptoms. 
Table II. Lung resistance $\left(\mathrm{cm} \mathrm{H}_{2} \mathrm{O} \cdot \mathrm{ml}^{-1} \cdot \mathrm{sec}^{-1}\right)$.

\begin{tabular}{|c|c|c|c|c|c|c|}
\hline Group & $\mathrm{N}$ & Baseline & 3.125 & 6.25 & 12.5 & 25 \\
\hline Control & 8 & $1.49 \pm 0.36$ & $2.20 \pm 0.55$ & $2.71 \pm 0.74$ & $3.00 \pm 0.71$ & $3.81 \pm 0.48$ \\
\hline OVA & 8 & $1.49 \pm 0.36$ & $3.11 \pm 0.34^{\mathrm{a}}$ & $7.66 \pm 0.53^{\mathrm{a}}$ & $11.09 \pm 1.28^{\mathrm{a}}$ & $19.79 \pm 1.48^{a}$ \\
\hline $\mathrm{OVA}+\mathrm{DMSO}$ & 8 & $1.49 \pm 0.36$ & $2.91 \pm 0.27$ & $7.59 \pm 0.50$ & $11.11 \pm 1.41$ & $19.31 \pm 1.04$ \\
\hline OVA + BMS-345541 & 8 & $1.49 \pm 0.36$ & $2.52 \pm 0.31^{\mathrm{b}}$ & $3.38 \pm 0.49^{c}$ & $4.59 \pm 0.72^{c}$ & $6.20 \pm 1.04^{\mathrm{c}}$ \\
\hline F-value & & $<0.001$ & 9.037 & 172.304 & 125.589 & 499.166 \\
\hline P-value & & 1.00 & $<0.001$ & $<0.001$ & $<0.001$ & $<0.001$ \\
\hline
\end{tabular}

Data are shown as the mean \pm standard deviation. ${ }^{a} \mathrm{P}<0.01$, compared with the control group; ${ }^{\mathrm{b}} \mathrm{P}<0.01$ and ${ }^{\mathrm{c}} \mathrm{P}<0.001$, compared with the $\mathrm{OVA}$ group. OVA, ovalbumin; DMSO, dimethyl sulfoxide.

Table III. Cell counts and percentages of inflammatory cells in the BALF.

\begin{tabular}{|c|c|c|c|c|c|c|}
\hline Group & $\mathrm{N}$ & Total cells $\left(10^{6} / 1\right)$ & Macrophages (\%) & Eosinophil (\%) & Lymphocytes (\%) & $\begin{array}{c}\text { Neutrophils } \\
(\%)\end{array}$ \\
\hline Control & 8 & $0.33 \pm 0.28$ & $41.56 \pm 4.44$ & $1.94 \pm 0.90$ & $32.19 \pm 5.80$ & $11.06 \pm 3.73$ \\
\hline OVA & 8 & $2.92 \pm 1.68^{\mathrm{a}}$ & $28.19 \pm 10.50$ & $15.08 \pm 3.26^{\mathrm{b}}$ & $39.31 \pm 3.39^{a}$ & $12.94 \pm 3.39$ \\
\hline $\mathrm{OVA}+\mathrm{DMSO}$ & 8 & $2.89 \pm 1.48$ & $38.31 \pm 9.86$ & $16.20 \pm 3.18$ & $39.94 \pm 5.41$ & $10.00 \pm 3.30$ \\
\hline OVA + BMS-345541 & 8 & $1.72 \pm 1.63^{\mathrm{c}}$ & $41.25 \pm 12.37$ & $3.81 \pm 1.25^{\mathrm{d}}$ & $36.81 \pm 2.80$ & $12.00 \pm 3.97$ \\
\hline F-value & & 11.354 & 1.803 & 80.080 & 7.013 & 0.976 \\
\hline P-value & & $<0.001$ & 0.169 & $<0.001$ & 0.001 & 0.418 \\
\hline
\end{tabular}

Data are shown as the mean \pm standard deviation. ${ }^{\text {a }} \mathrm{P}<0.05$ and ${ }^{\mathrm{b}} \mathrm{P}<0.01$, compared with the control group; ${ }^{\mathrm{c}} \mathrm{P}<0.05$ and ${ }^{\mathrm{d}} \mathrm{P}<0.01$, compared with the OVA group. OVA, ovalbumin; DMSO, dimethyl sulfoxide.

Table IV. Epithelial thickness.

\begin{tabular}{lcc}
\hline Group & $\mathrm{N}$ & Epithelial thickness $(\mu \mathrm{m})$ \\
\hline Control & 8 & $8.85 \pm 3.15$ \\
OVA & 8 & $28.02 \pm 8.09^{\mathrm{a}}$ \\
OVA + DMSO & 8 & $27.81 \pm 5.93$ \\
OVA + BMS-345541 & 8 & $10.71 \pm 4.18^{\mathrm{b}}$ \\
F-value & & 27.545 \\
P-value & & $<0.001$
\end{tabular}

Data are shown as the mean \pm standard deviation. ${ }^{a} \mathrm{P}<0.001$, compared with the control group; ${ }^{b} \mathrm{P}<0.001$, compared with the OVA group. OVA, ovalbumin; DMSO, dimethyl sulfoxide.

Effect of BMS-345541 on airway responsiveness. To evaluate the effect of BMS-345541 on AHR in response to Ach, the RL was measured in an invasive whole-body plethysmography chamber in anesthetized mice. No significant differences in baseline airway resistance were observed among the four groups. The administration of Ach at doses increasing progressively between 3.125 and $25 \mathrm{mg} / \mathrm{ml}$ led to markedly increased RL values in the OVA group compared with those in the control group $(\mathrm{P}<0.001)$. However, compared with the OVA group, treatment with BMS-345541 resulted in a significant decrease

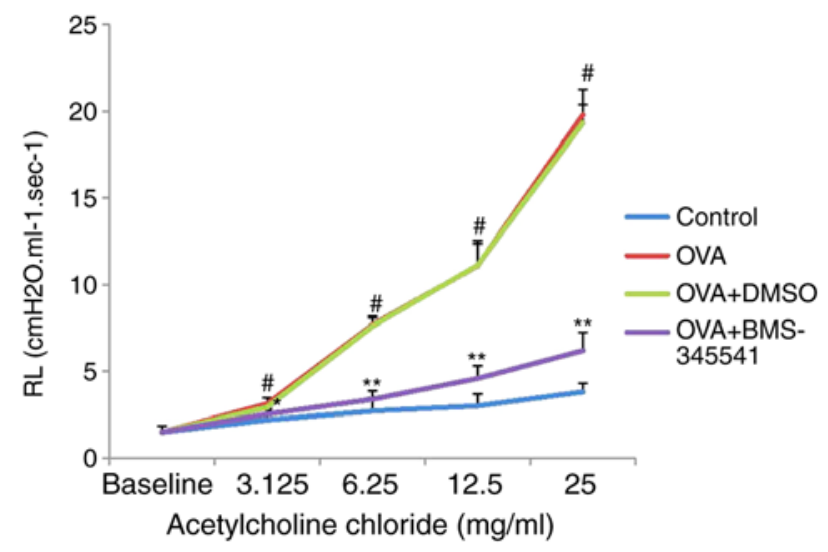

Figure 2. BMS-345541 suppresses airway hyperactivity in OVA-sensitized mice. Data are presented as the mean \pm standard deviation ( $n=8$ per group). ${ }^{\#} \mathrm{P}<0.001$, OVA group, compared with the control group; ${ }^{*} \mathrm{P}<0.01$ and ${ }^{* *} \mathrm{P}<0.001$, OVA + BMS-345541 group compared with the OVA group. RL, lung resistance; OVA, ovalbumin; DMSO, dimethyl sulfoxide.

in $\mathrm{RL}(\mathrm{P}<0.01)$. The change in $\mathrm{RL}$ in the OVA + DMSO group was close to that in the OVA group (Fig. 2, Table II).

Effect of BMS-345541 on airway inflammation and remodeling. Airway inflammation is characterized by the infiltration of inflammatory cells. The degree of airway inflammation was evaluated via histopathological analysis of lung lesions (H\&E 


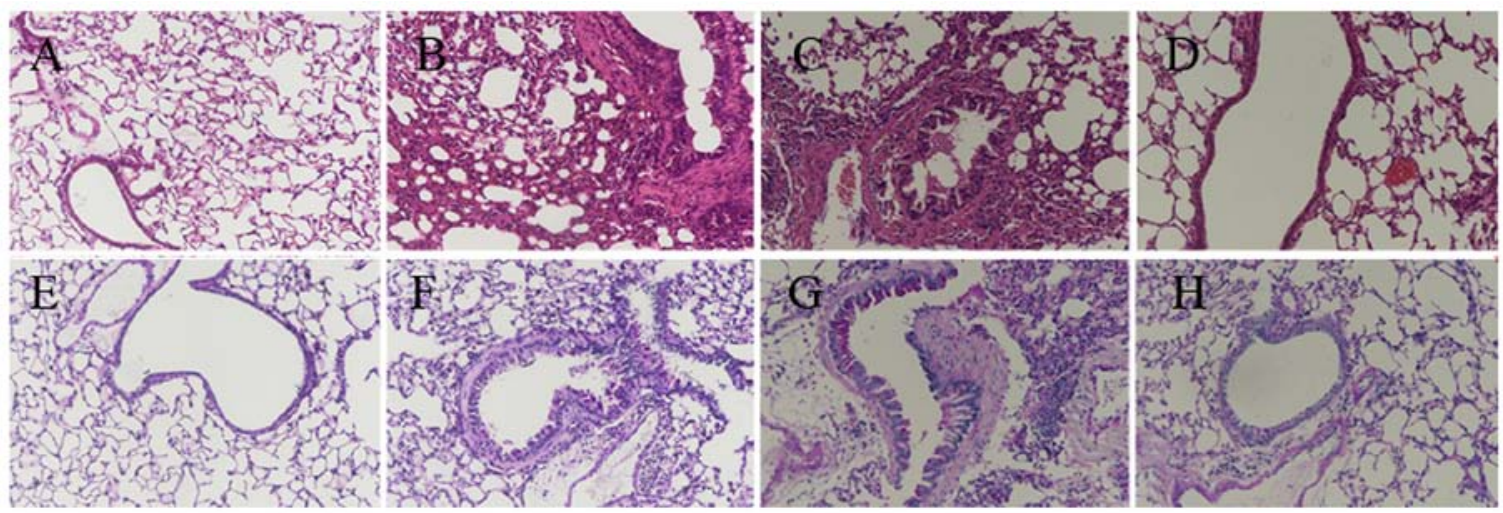

Figure 3. BMS-345541 attenuates airway inflammation, airway goblet cell hyperplasia and mucus production in OVA-induced asthmatic mice. Hematoxylin and eosin staining in (A) control, (B) OVA, (C) OVA + DMSO and (D) OVA + BMS-345541. Periodic acid-Schiff staining of (E) control, (F) OVA, (G) OVA + DMSO and (H) OVA + BMS-345541. Original magnification, x200. OVA, ovalbumin; DMSO, dimethyl sulfoxide.
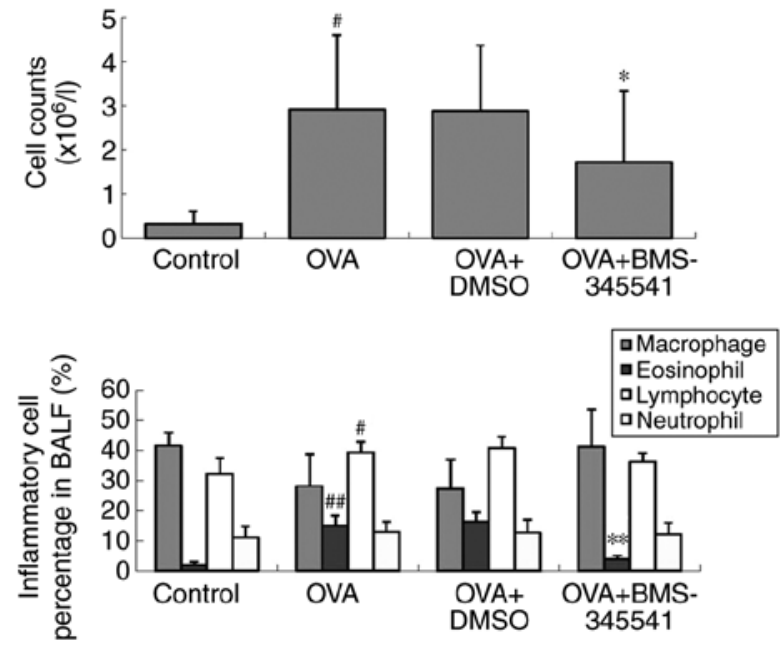

Figure 4. BMS-345541 inhibits inflammatory cell accumulation in the BALF in a mouse model of asthma. In the OVA + BMS-345541 group, the cell counts and percentages of eosinophils in the BALF were decreased. The data are presented as the mean \pm standard deviation ( $\mathrm{n}=8$ per group). ${ }^{\mathrm{H}} \mathrm{P}<0.05$ and ${ }^{\# \#} \mathrm{P}<0.01$, OVA group compared with the control group; ${ }^{*} \mathrm{P}<0.05$ and ${ }^{* *} \mathrm{P}<0.01$, OVA + BMS-345541 group compared with the OVA group. OVA, ovalbumin; BALF, bronchoalveolar lavage fluid; DMSO, dimethyl sulfoxide.

staining; Fig. 3A-D), and by total cell counts and inflammatory cell percentage, including eosinophils, lymphocytes, neutrophils and macrophages, in the BALF. The mice in the OVA and OVA + DMSO groups exhibited an influx of inflammatory cells around the bronchi and bronchioles along with submucosal edema, as shown in Fig. 3B and C. The total cell numbers and the percentages of eosinophil and lymphocytes were higher in the OVA-induced mice than those in the control group. By contrast, the BMS-345541 treatment group exhibited less inflammatory cell infiltration and edema.

Goblet cell hyperplasia is one of the critical pathophysiologic changes in the airway remodeling of asthma (24). PAS staining was used to evaluate airway global cell hyperplasia and mucus production (Fig. 3E-H). The lung tissue from the OVA mice (Fig. 3F) exhibited airway remodeling compared with that in the control group (Fig. 3E), including the enlargement of airway smooth muscle, basement membrane thickening, goblet cell hyperplasia, mucus hypersecretion, and

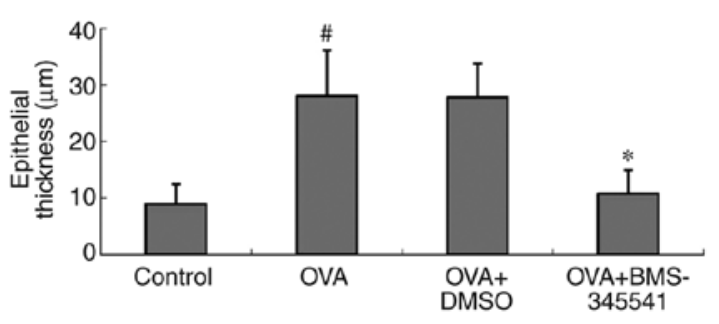

Figure 5. BMS-345541 attenuates airway remodeling in a mouse model of asthma. Epithelial thickness was measured by Image Pro Plus 6.0 image-analysis software. Average measurements were obtained. The data are presented as the mean \pm standard deviation ( $\mathrm{n}=8$ per group). ${ }^{\text {}} \mathrm{P}<0.001$, OVA group compared with the control group; ${ }^{*} \mathrm{P}<0.001$, OVA + BMS-345541 group compared with the OVA group. OVA, ovalbumin; DMSO, dimethyl sulfoxide.

epithelium damage. The OVA + DMSO group (Fig. 3G) exhibited similar changes. However, the development of airway remodeling was significantly attenuated by the administration of BMS-345541. Despite inflammatory changes, the mice in the OVA + BMS-345541 group showed only marginal bronchial wall thickening, airway stenosis and epithelial damage (Fig. 3H).

Following BMS-345541 treatment, the increased cell counts and eosinophil percentages were markedly decreased compared with the corresponding values in the OVA mice $(\mathrm{P}<0.05)$. There was no change between the OVA and OVA + DMSO groups (Fig. 4, Table III).

The epithelial thicknesses were examined to assess the features of airway remodeling. A quantitative assessment of epithelial thickness demonstrated significant increases in the OVA group $(28.02 \pm 8.09 \mu \mathrm{m})$ and the OVA + DMSO group $(27.80 \pm 5.93 \mu \mathrm{m})$. There was a significant difference between the OVA and the control groups $(\mathrm{P}<0.001)$. However, the epithelial thickness was markedly alleviated by the administration of BMS-345541 $(10.71 \pm 4.18 \mu \mathrm{m})$. There was also a significant difference between the OVA + BMS-345541 and the OVA groups $(\mathrm{P}<0.001)$ (Fig. 5, Table IV).

Effect of BMS-345541 on the concentrations of TGF $\beta 1$ in serum and $B A L F$. TGF $\beta 1$ is an important cytokine involved in airway remodeling, and is important in EMT (25). TGF $\beta 1$ mediates tissue inflammation in asthma (26). Concentrations of 
Table V. TGF $\beta 1$ concentration in serum and BALF.

\begin{tabular}{lccc}
\hline Group & $\mathrm{N}$ & Serum $(\mathrm{pg} / \mathrm{ml})$ & BALF $(\mathrm{pg} / \mathrm{ml})$ \\
\hline Control & 8 & $31.53 \pm 14.41$ & $20.98 \pm 13.29$ \\
OVA & 8 & $84.41 \pm 38.18^{\mathrm{a}}$ & $44.36 \pm 10.98^{\mathrm{a}}$ \\
OVA + DMSO & 8 & $89.63 \pm 28.62$ & $46.58 \pm 16.27$ \\
OVA + BMS-345541 & 8 & $42.04 \pm 28.38^{\mathrm{c}}$ & $25.45 \pm 14.15^{\mathrm{b}}$ \\
F-value & & 8.405 & 7.109 \\
P-value & & $<0.001$ & 0.001 \\
\hline
\end{tabular}

Data are shown as the mean \pm standard deviation. ${ }^{\text {a }} \mathrm{P}<0.01$, compared with the control group; ${ }^{\mathrm{b}} \mathrm{P}<0.05$ and ${ }^{\mathrm{c}} \mathrm{P}<0.01$, compared with the OVA group. BALF, bronchoalveolar lavage fluid; OVA, ovalbumin; DMSO, dimethyl sulfoxide.

Table VI. IOD of E-cadherin and vimentin expression.

\begin{tabular}{lccc}
\hline Group & $\mathrm{N}$ & E-cadherin & Vimentin \\
\hline Control & 8 & $0.34 \pm 0.28$ & $0.08 \pm 0.06$ \\
OVA & 8 & $0.05 \pm 0.04^{\mathrm{a}}$ & $0.43 \pm 0.33^{\mathrm{a}}$ \\
OVA + DMSO & 8 & $0.05 \pm 0.05$ & $0.40 \pm 0.23$ \\
OVA + BMS-345541 & 8 & $0.22 \pm 0.07^{\mathrm{b}}$ & $0.17 \pm 0.04^{\mathrm{b}}$ \\
F-value & & 7.164 & 5.716 \\
P-value & & 0.001 & 0.003 \\
\hline
\end{tabular}

Data are shown as the mean \pm standard deviation. ${ }^{a} \mathrm{P}<0.01$, compared with the control group, ${ }^{\mathrm{b}} \mathrm{P}<0.01$, compared with the OVA group. OVA, ovalbumin; DMSO, dimethyl sulfoxide.

TGF $\beta 1$ in the serum and BALF were detected by ELISA, and it was found that the OVA group had markedly elevated levels of serum and BALF TGF $\beta 1$, compared with the control group. No difference between the OVA and OVA + DMSO groups was found. However, unlike in the OVA + DMSO group, the concentrations of TGF $\beta 1$ in the BMS-345541-treated OVA group were significantly decreased compared with those in the OVA group (Fig. 6, Table V).

Effect of BMS-345541 on the expression of E-cadherin and vimentin as assessed by immunohistochemistry, RT-qPCR and western blot analyses. The epithelial marker E-cadherin and the mesenchymal marker vimentin are important markers of EMT. The expression levels of E-cadherin and vimentin were estimated by immunohistochemical image analysis. The mRNA and protein levels of E-cadherin and vimentin were determined by RT-qPCR and western blot analyses. As shown in Fig. 7A-G, the results of the immunohistochemistry indicated a significant decrease in the expression of E-cadherin and an increase in the expression of vimentin in the epithelium of the OVA-induced mice (Fig. 7B and G). Following the daily administration of BMS-345541, the expression of E-cadherin was increased, whereas the expression of vimentin was decreased, as shown in Fig. 7D and I. No E-cadherin or vimentin was identified in the negative controls (Fig. 7E and J).

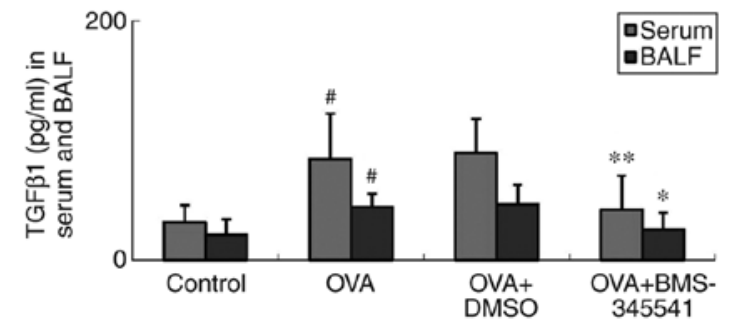

Figure 6. BMS-345541 decreases the levels of TGF $\beta 1$ in the serum and BALF in a mouse model of asthma, as analyzed by enzyme-linked immunosorbent assay. The values are expressed as the mean \pm standard deviation $(n=8$ per group). " $\mathrm{P}<0.01$, OVA group compared with the control group; ${ }^{*} \mathrm{P}<0.05$ and ${ }^{* *} \mathrm{P}<0.01$, OVA + BMS-345541 group compared with the OVA group. OVA, ovalbumin; BALF, bronchoalveolar lavage fluid; TGF $\beta 1$, transforming growth factor $\beta 1$; DMSO, dimethyl sulfoxide.

As shown in Fig. 8 and Table VI, the expression of EMT markers was further investigated by IOD measurement. It was found that the IOD value of vimentin was higher in the OVA group and the OVA + DMSO group, whereas the IOD value in the OVA + BMS-345541 group decreased significantly. By contrast, it was found that the E-cadherin IOD values were decreased in the OVA and OVA + DMSO groups, and increased in the OVA + BMS-345541 group following BMS-345541 administration. There were significant differences between the OVA and the control groups $(\mathrm{P}<0.01)$, and the OVA and OVA + BMS-345541 groups $(\mathrm{P}<0.05)$. No significant difference was observed between the OVA and the OVA + DMSO groups.

The mRNA and protein levels showed the same results, which were consistent with the immunohistochemical results. As shown in Fig. 9A-D and Table VII, the same results were observed for the expression of E-cadherin, which was downregulated, and expression of vimentin, which was upregulated, in the OVA group mice. BMS-345541 supressed the expression of vimentin and promoted the expression of E-cadherin. These results indicated that BMS-345541 regulated the EMT process in mice with asthma, whereas DMSO did not have a similar effect.

\section{Discussion}

Asthma is a chronic inflammatory disorder, and the predisposing factors and pathogenesis of asthma are complicated. In the present study, mice were challenged with OVA to produce an allergy model of asthma. Normal control and DMSO therapeutic control groups were set up in this experiment. On the basis of this mouse asthma model, EMT characteristics, airway inflammation, airway remodeling, and airway reactivity were investigated in the asthmatic mice. Additionally, the treatment effects of BMS-345541 on OVA-induced asthmatic mice were observed, and the molecular regulation and intervention mechanisms of this treatment in the airway remodeling of asthma were examined.

In the experiment, mice in the OVA group exhibited a variety of asthma-related symptoms. AHR is an important characteristic feature of asthma. Several factors contribute to its development. The administration of Ach at progressively increasing doses led to a marked increase in RL in the OVA 


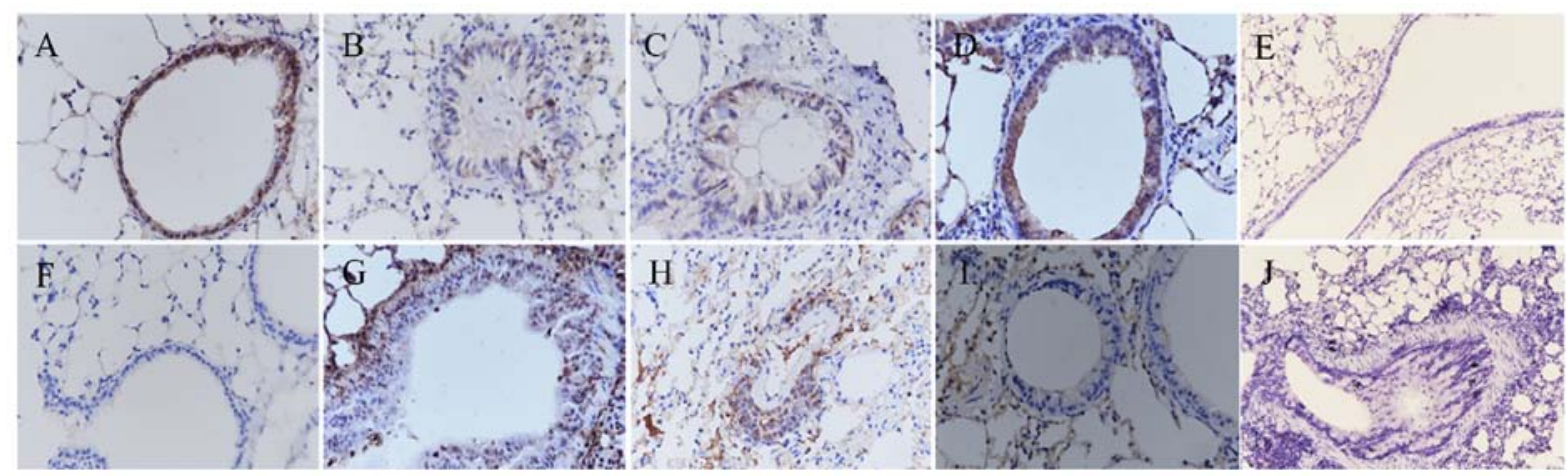

Figure 7. BMS-345541 inhibits epithelial-mesenchymal transition in asthma. Immunohistochemistry images (magnification, $\mathrm{x} 400$ ) of E-cadherin in the (A) control, (B) OVA, (C) OVA + DMSO, and (D) OVA + BMS-345541 groups; (E) negative control of E-cadherin. Images of vimentin in the (F) control, (G) OVA, (H) OVA + DMSO, (I) OVA + BMS-345541; (J) negative control of vimentin. Staining in pulmonary tissue sections is shown for all groups. OVA, ovalbumin; DMSO, dimethyl sulfoxide.

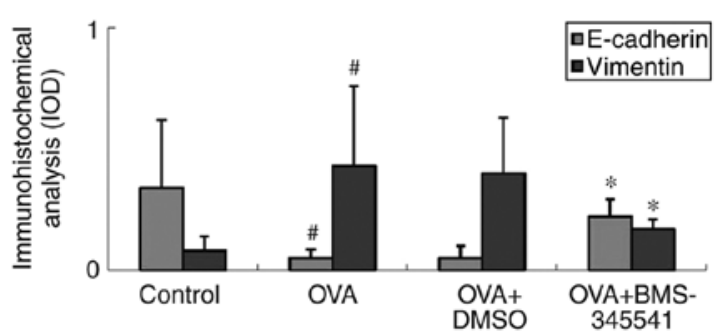

Figure 8. Mean IOD detection using an image-analysis system in immunohistochemistry sections. Compared with the values in the OVA-induced asthmatic mice, the E-cadherin expression IOD was increased, whereas the vimentin expression IOD was decreased in the BMS-345541-treated group. The values are expressed as the mean \pm standard deviation $(\mathrm{n}=8$ per group). ${ }^{\text {"P}}<0.01$, OVA group compared with the control group; ${ }^{*} \mathrm{P}<0.05$, OVA + BMS-345541 group compared with the OVA group. IOD, integrated optical density; OVA, ovalbumin; DMSO, dimethyl sulfoxide.

asthma group. These results showed that the OVA-induced asthmatic mice exhibited AHR.

Airway inflammation is central to asthma pathophysiology and considered to be the key trigger of AHR. The development of airway inflammation involves a large number of inflammatory cells, particularly eosinophils, infiltrating the lung tissue, gathering around the bronchus, and periodically infiltrating into the BALF. Eosinophils are required for the occurrence of airway remodeling. The hypersecretion of airway mucus, produced and secreted from goblet cells, is an important cause of airway obstruction, asthma deterioration and fatal asthma (27). In the present study, the OVA group exhibited significant inflammatory cell infiltration around the blood vessels and bronchi, submucosal edema, increased numbers of total cells, and an increased percentage of eosinophils in the BALF, compared with the control group. The lung tissue from mice in the OVA group exhibited airway remodeling, including enlargement of airway smooth muscle, basement membrane thickening, epithelial damage, subepithelial fibrosis, goblet cell hyperplasia, and mucus hypersecretion. All these observations suggested that the asthmatic signs of airway inflammation and airway remodeling were established successfully in the OVA-induced mouse model.

TGF $\beta$ has three isomers (TGF $\beta 1$, TGF $\beta 2$, and TGF $\beta 3$ ), which show a high degree of homology. Among them, TGF $\beta 1$
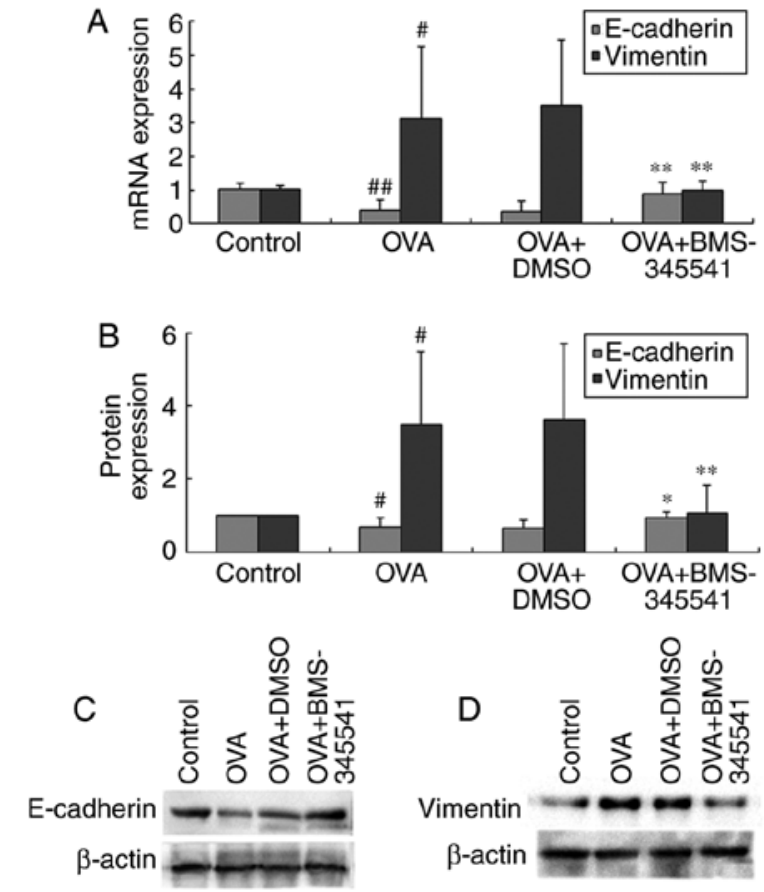

Figure 9. BMS-345541 inhibits epithelial-mesenchymal transition in asthma. mRNA levels of E-cadherin and vimentin in mouse lung tissues were measured by (A) reverse transcription-quantitative polymerase chain reaction analysis. (B) Protein levels were measured by western blot analysis for (C) E-cadherin and (D) vimentin. Data are presented as the mean \pm standard deviation ( $\mathrm{n}=8$ per group). ${ }^{\#} \mathrm{P}<0.01$ and ${ }^{\# \#} \mathrm{P}<0.001$, OVA group compared with the control group; ${ }^{*} \mathrm{P}<0.05$ and ${ }^{* *} \mathrm{P}<0.01$, OVA + BMS-345541 group compared with the OVA group. OVA, ovalbumin; DMSO, dimethyl sulfoxide.

is important in biological functions. It remains controversial whether TGF $\beta 1$ has different roles in the differentiation, expression of contractile proteins, and mediation of the proliferation of airway cells (28). The mechanisms underlying the effects of TGF $\beta 1$ on asthma remain to be fully elucidated. There are various hypotheses regarding the role of TGF $\beta 1$ in asthma. The majority of studies have shown that TGF $\beta 1$ can trigger EMT (29) and that it is important in the onset of asthma and airway remodelling (25). TGF $\beta 1$ is a remodeling related mediator; additionally, the increased secretion of TGF $\beta 1$ induced by asthmatic chronic inflammation may 
Table VII. mRNA and protein expression levels of E-cadherin and vimentin.

\begin{tabular}{|c|c|c|c|c|c|}
\hline \multirow[b]{2}{*}{ Group } & \multirow[b]{2}{*}{$\mathrm{N}$} & \multicolumn{2}{|c|}{ E-cadherin } & \multicolumn{2}{|c|}{ Vimentin } \\
\hline & & mRNA & Protein & mRNA & Protein \\
\hline Control & 8 & $1.03 \pm 0.16$ & $1.00 \pm 0.00$ & $1.02 \pm 0.10$ & $1.00 \pm 0.00$ \\
\hline OVA & 8 & $0.38 \pm 0.33^{\mathrm{b}}$ & $0.69 \pm 0.24^{\mathrm{a}}$ & $3.10 \pm 2.14^{\mathrm{a}}$ & $3.48 \pm 2.02^{\mathrm{a}}$ \\
\hline OVA + DMSO & 8 & $0.36 \pm 0.33$ & $0.66 \pm 0.22$ & $3.49 \pm 1.96$ & $3.62 \pm 2.09$ \\
\hline OVA + BMS-345541 & 8 & $0.89 \pm 0.35^{\mathrm{d}}$ & $0.94 \pm 0.16^{\mathrm{c}}$ & $1.00 \pm 0.28^{\mathrm{d}}$ & $1.05 \pm 0.78^{\mathrm{d}}$ \\
\hline F-value & & 10.370 & 7.805 & 6.670 & 7.501 \\
\hline P-value & & $<0.001$ & 0.001 & 0.002 & 0.001 \\
\hline
\end{tabular}

Data are shown as the mean \pm standard deviation. ${ }^{\mathrm{a}} \mathrm{P}<0.01$ and ${ }^{\mathrm{b}} \mathrm{P}<0.001$, compared with the control group; ${ }^{\mathrm{c}} \mathrm{P}<0.05$ and ${ }^{\mathrm{d}} \mathrm{P}<0.01$, compared with the OVA group. OVA, ovalbumin; DMSO, dimethyl sulfoxide.

result in EMT, which is one of the most important mechanisms of airway inflammation and airway remodeling in asthma (7). The present study detected TGF $\beta 1$ concentrations in mouse serum and BALF samples by ELISA. The mice in the OVA group exhibited increased expression of TGF $\beta 1$ in serum and BALF. These findings indicated that TGF $\beta 1$ was associated with the inflammation and airway hyperactivity in asthma.

The E-cadherin and vimentin proteins are considered to be critical biomarkers of EMT (30). The loss of E-cadherin, a cell-cell adhesion protein, disrupts epithelial barrier function and causes the bronchial epithelium to lose its structural stability and polarity, which is necessary for bronchial epithelial cell migration. The increased expression of vimentin, an intermediate filament protein, alters the cytoskeletal protein composition and thus drives the transformation of epithelial-derived cubic-shaped cells into spindle-shaped fibre-like cells, which subsequently gain the ability to migrate (31). A previous study found that the expression of E-cadherin decreased and that of vimentin increased in airway epithelial cells from asthmatic mice exposed to dust mites (32). Furthermore, lower expression of E-cadherin in patients with asthma has been associated with more severe loss of airway barrier function, which promotes the development of airway remodelling (33). In the present study, the expression of E-cadherin was downregulated and the expression of vimentin was upregulated in mice in the OVA group. These results further confirmed the role of TGF $\beta 1$-induced EMT on airway remodeling, and suggested that it promotes airway inflammation and is involved in the pathogenesis of asthma.

The NF- $\mathrm{KB}$ signaling pathway is central in the pathogenesis of airway inflammation in asthma (34). NF- $\kappa B$ is already under consideration as a promising novel target for the treatment of asthma. Inhibition of the NF- $\mathrm{KB}$ pathway by inhibitors has been shown to attenuate allergic airway inflammation in mice (35). IKK $\beta$, the target of BMS-345541, is a key positive regulator of NF- $\mathrm{KB}$. The inhibition of IKK $\beta$ inhibits the activation of NF- $\kappa B$. BMS-345541 is a highly selective inhibitor of IкB kinase, which binds at an allosteric site of the enzyme and inhibits NF-kB-dependent transcription in mice (36). BMS-345541 does not bind to the ATP binding site, and oral BMS-345541 is well tolerated by mice. A previous study found that mice administered with a prophylactic dose of BMS-345541 exhibited no toxicological changes, even at the efficacious dose of $100 \mathrm{mg} / \mathrm{kg}$ (15). Therefore, BMS-345541 is considered safe and particularly well suited to the investigation of the use of IKK inhibitors in murine models of inflammation. BMS-345541 remains at micromolar serum drug levels for several hours following an oral dose and is biochemically active in mice (37). Treatment with varying doses of BMS-345541 (10-100 mg/kg, p.o.) can inhibit inflammation in mice to different degrees, with a high dosage $(100 \mathrm{mg} / \mathrm{kg})$ of BMS-345541 showing therapeutic effects comparable with the effects of glucocorticoid treatments (15).

In the preliminary experiments of the present study, normal female BALB/c mice (aged 6-8 weeks, weighing $25 \pm 3 \mathrm{~g}$ ) were fed with BMS-345541 or DMSO for 7 days. None of the mice showed abnormal behavior or death during this process. In addition, lung samples from the mice were stained with H\&E to observe their pathological features, and no changes were found from the observations in the control mice. Therefore, BMS-345541 and DMSO were considered safe and non-toxic. This finding was similar to the results of previous studies $(15,38)$.

Subsequent experiments performed in the present study aimed to examine the therapeutic effect of BMS-345541, in which $50 \mathrm{mg} / \mathrm{kg}$ BMS-345541 was used to treat OVA-induced asthma in mice, with DMSO used as the therapeutic control vehicle simultaneously. It was found that the asthma symptoms were relieved by BMS-345541 treatment, with RL values significantly decreased, compared with the values in the OVA and OVA + DMSO groups. In addition, following BMS-345541 treatment, there were a series of other changes, whereas DMSO had no similar effects. In the OVA + BMS-345541 group, histopathological changes of lung lesions, including epithelial thickening, bronchospasm, inflammatory cell infiltration, and mucus secretion, were significantly reduced. The BMS-345541 treatment group exhibited less inflammatory cell infiltration, and the cell count and eosinophil percentage were markedly decreased. The levels of TGF $\beta 1$ in the BALF and serum were also decreased. BMS-345541 treatment was accompanied by the upregulated expression of the epithelial marker E-cadherin 
and downregulated expression of the mesenchymal marker vimentin, which was verified by immunohistochemistry, RT-qPCR and western blot analyses. These changes in EMT marker protein expression were inhibited by BMS-345541 treatment. Therefore, these results further confirmed that BMS-345541 inhibited the production of TGF $\beta 1$ and ameliorated airway hyperresponsiveness via the inhibition of IKK $\beta$. BMS-345541 treatment protected from OVA-induced allergic airway inflammation and attenuated EMT in airway remodeling in asthmatic mice.

The present study had a number of limitations, including the fact that there was no investigation of the effect of BMS-345541 on lung immune cells, including CD3, CD4, CD8, regulatory T, T helper 17, and B cells. There was also no investigation of changes resulting from BMS-345541 to major secretory mucins, including MUC5AC and MUC5B, nor were changes to major extracellular matrix components investigated. There was also no investigation of fundamental inflammatory mediators in the pathogenesis of bronchial asthma, including IgE, interleukin (IL)-4, IL-5, IL-5 receptor, and IL-13. In the future, these limitations are to be addressed. Similar to previous studies, as bronchial specimens are not easily acquired in mice, the lungs of the mice were selected and harvested for histopathology to obtain supernatants following lung homogenization and to obtain nuclear and protein extracts to detect the mRNA and protein levels of E-cadherin and vimentin. Future investigations aim to obtain bronchial specimens for confirmation of the results. In addition, only the preliminary experiments included BMS-345541 alone and DMSO alone control groups, which were not included in later experiments and presents another limitation of the study. Further improvements are required in the future.

In conclusion, an allergic asthmatic mouse model can be established successfully by OVA sensitization and challenge. Asthmatic mice in this model have the typical airway inflammation, airway hyperresponsiveness and airway remodeling observed in asthma. Airway remodeling is observed in OVA-treated asthmatic mice, in addition to evidence of EMT. The increased secretion of TGF $\beta 1$ by asthmatic inflammation may result in EMT. TGF $\beta 1, \mathrm{NF}-\kappa \mathrm{B}$ and EMT are important for asthma. The IKK $\beta$ inhibitor, BMS-345541, had a therapeutic effect on asthma airway inflammation and airway remodeling. The therapeutic mechanism may be achieved through decreasing the expression of TGF $\beta 1$, inhibiting the activation of $N F-\kappa B$ and reducing EMT. The results of the present study provide an experimental basis for the potential use of IKK $\beta$ inhibitors as therapeutics in the clinical treatment of asthma. IKK $\beta$ inhibitors may be promising candidates for pharmacologic agents to use in future human asthma therapy.

\section{Acknowledgements}

The authors would like to acknowledge the facilities supported by the Clinical Laboratory and the Central Laboratory of Jiangxi Children's Hospital, and the Central Laboratory of Jiangxi People's Hospital.

\section{Funding}

This study was supported by the Technology and Science Foundation of Jiangxi Province (no. 20151BBB70267).

\section{Availability of data and materials}

All data generated or analyzed during this study are included in this published article.

\section{Authors' contributions}

XZ performed all the experiments and statistical analyses. QL, GH and JW were involved in the design of the study. QH, ZL, $\mathrm{GW}$ and $\mathrm{YZ}$ performed part of the experiments. All authors have read and approved the final manuscript.

\section{Ethics approval and consent to participate}

The animal experiments were approved by the Medical Ethics Committee of Jiangxi People's Hospital (2015084).

\section{Patient consent for publication}

Not applicable.

\section{Competing interests}

The authors declare that they have no competing interests.

\section{References}

1. Killeen K and Skora E: Pathophysiology, diagnosis, and clinical assessment of asthma in the adult. Nurs Clin North Am 48: 11-23, 2013.

2. Holgate ST: Pathogenesis of asthma. Clin Exp Allergy 38: 872-897, 2008

3. Bergmann KC: Bronchial asthma-many types, different therapies. Dtsch Med Wochenschr 141: 687-692, 2016 (In German).

4. Hirota N and Martin JG: Mechanisms of airway remodeling. Chest 144: 1026-1032, 2013.

5. Gras D, Bourdin A, Chanez P and Vachier I: Airway remodeling in asthma: Clinical and functional correlates. Med Sci (Paris) 27: 959-965, 2011 (In French).

6. Fischer KD and Agrawal DK: Vitamin D regulating TGF- $\beta$ induced epithelial-mesenchymal transition. Respir Res 15: 146, 2014.

7. Tian X, Tian X, Huo R, Chang Q, Zheng G, Du Y, Chen Y and Niu B: Bacillus Calmette-Guerin alleviates airway inflammation and remodeling by preventing TGF- $\beta_{1}$ induced epithelial-mesenchymal transition. Hum Vaccin Immunother 13: 1758-1764, 2017.

8. Kalita M, Tian B, Gao B, Choudhary S, Wood TG, Carmical JR, Boldogh I, Mitra S, Minna JD and Brasier AR: Systems approaches to modeling chronic mucosal inflammation. Biomed Res Int 2013: 505864, 2013

9. Ijaz T, Pazdrak K, Kalita M, Konig R, Choudhary S, Tian B, Boldogh I and Brasier AR: Systems biology approaches to understanding Epithelial Mesenchymal transition (EMT) in mucosal remodeling and signaling in asthma. World Allergy Organ J 7: $13,2014$.

10. Loffredo LF, Abdala-Valencia H, Anekalla KR, Cuervo-Pardo L, Gottardi CJ and Berdnikovs S: Beyond epithelial-to-mesenchymal transition: Common suppression of differentiation programs underlies epithelial barrier dysfunction in mild, moderate, and severe asthma. Allergy 72: 1988-2004, 2017.

11. Berair R and Brightling CE: Asthma therapy and its effect on airway remodelling. Drugs 74: 1345-1369, 2014.

12. Zhao Y, Tian B, Sadygov RG, Zhang Y and Brasier AR: Integrative proteomic analysis reveals reprograming tumor necrosis factor signaling in epithelial mesenchymal transition. J Proteom 148: 126-138, 2016.

13. Gagliardo R, Chanez P, Profita M, Bonanno A, Albano GD, Montalbano AM, Pompeo F, Gagliardo C, Merendino AM and Gjomarkaj M: IкB kinase-driven nuclear factor- $\kappa$ B activation in patients with asthma and chronic obstructive pulmonary disease. J Allergy Clin Immunol 128: 635-645.e1-e2, 2011. 
14. Tian F, Zhou P, Kang W, Luo L, Fan X, Yan J and Liang H: The small-molecule inhibitor selectivity between IKK $\alpha$ and IKK $\beta$ kinases in NF- $\kappa \mathrm{B}$ signaling pathway. J Recept Signal Transduct Res 35: 307-318, 2015.

15. McIntyre KW, Shuster DJ, Gillooly KM, Dambach DM, Pattoli MA,Lu P,Zhou XD, Qiu Y,Zusi FC and Burke JR: A highly selective inhibitor of I kappa B kinase, BMS-345541, blocks both joint inflammation and destruction in collagen-induced arthritis in mice. Arthritis Rheum 48: 2652-2659, 2003.

16. Caramori G, Adcock IM and Ito K: Anti-inflammatory inhibitors of IkappaB kinase in asthma and COPD. Curr Opin Investig Drugs 5: 1141-1147, 2004.

17. Pattoli MA, MacMaster JF, Gregor KR and Burke JR: Collagen and aggrecan degradation is blocked in interleukin-1-treated cartilage explants by an inhibitor of IkappaB kinase through suppression of metalloproteinase expression. J Pharmacol Exp Ther 315: 382-388, 2005.

18. Ping H, Yang F, Wang M, Niu Y and Xing N: IKK inhibitor suppresses epithelial-mesenchymal transition and induces cell death in prostate cancer. Oncol Rep 36: 1658-1664, 2016

19. Li H, Han W, Polosukhin V, Yull FE, Segal BH, Xie CM and Blackwell TS: NF- $\kappa B$ inhibition after cecal ligation and puncture reduces sepsis-associated lung injury without altering bacterial host defense. Mediators Inflamm 2013: 503213, 2013.

20. Wang ZW, Li RK, Ren Y, Liu XF, Cheng XL and Tuo HY: Establishment and evaluation of a mouse model of bronchial asthma with Yin deficiency syndrome. Zhongguo Ying Yong Sheng Li Xue Za Zhi 31: 556-560, 2015.

21. Yao J, Jiang M, Zhang Y, Liu X, Du Q and Feng G: Chrysin alleviates allergic inflammation and airway remodeling in a murine model of chronic asthma. Int Immunopharmacol 32: 24-31, 2016

22. Yao T, Ying X, Zhao Y, Yuan A, He Q, Tong H, Ding S, Liu J, Peng X, Gao E, et al: Vitamin D receptor activation protects against myocardial reperfusion injury through inhibition of apoptosis and modulation of autophagy. Antioxid Redox Signal 22: 633-650, 2015.

23. Livak KJ and Schmittgen TD: Analysis of relative gene expression data using real-time quantitative PCR and the 2(-Delta Delta C(T)) method. Methods 25: 402-408, 2001.

24. Ordoñez CL, Khashayar R, Wong HH, Ferrando R, Wu R, Hyde DM, Hotchkiss JA, Zhang Y, Novikov A, Dolganov G and Fahy JV: Mild and moderate asthma is associated with airway goblet cell hyperplasia and abnormalities in mucin gene expression. Am J Respir Crit Care Med 163: 517-523, 2001.

25. Shi J, Chen M, Ouyang L, Huang L, Lin X, Zhang W, Liang R, Lv Z, Liu S and Jiang S: Airway smooth muscle cells from ovalbumin-sensitized mice show increased proliferative response to TGF $\beta 1$ due to up-regulation of Smad3 and TGF $\beta R I I$. J Asthma 54: 467-475, 2017.

26. Dimitropoulou C, Drakopanagiotakis F, Chatterjee A, Snead C and Catravas JD: Estrogen replacement therapy prevents airway dysfunction in a murine model of allergen-induced asthma. Lung 187: 116-127, 2009.
27. Rogers DF: Physiology of airway mucus secretion and pathophysiology of hypersecretion. Respir Care 52: 1134-1149, 2007.

28. Ojiaku CA, Yoo EJ and Panettieri RA Jr: Transforming growth factor $\beta 1$ function in airway remodeling and hyperresponsiveness. The missing link? Am J Respir Cell Mol Biol 56: 432-442, 2017.

29. Yang YC, Zhang N, Van Crombruggen K, Hu GH, Hong SL and Bachert C: Transforming growth factor-betal in inflammatory airway disease: A key for understanding inflammation and remodeling. Allergy 67: 1193-1202, 2012.

30. Scanlon CS, Van Tubergen EA, Inglehart RC and D'Silva NJ: Biomarkers of epithelial-mesenchymal transition in squamous cell carcinoma. J Dent Res 92: 114-121, 2013.

31. Kokkinos MI, Wafai R, Wong MK, Newgreen DF, Thompson EW and Waltham M: Vimentin and epithelial-mesenchymal transition in human breast cancer-observations in vitro and in vivo. Cells Tissues Organs 185: 191-203, 2007.

32. Fischer KD, Hall SC and Agrawal DK: Vitamin D supplementation reduces induction of epithelial-mesenchymal transition in allergen sensitized and challenged mice. Plos One 11: e0149180, 2016.

33. de Boer WI, Sharma HS, Baelemans SM, Hoogsteden HC, Lambrecht BN and Braunstahl GJ: Altered expression of epithelial junctional proteins in atopic asthma: Possible role in inflammation. Can J Physiol Pharmacol 86: 105-112, 2008.

34. Schuliga M: NF-kappaB signaling in chronic inflammatory airway disease. Biomolecules 5: 1266-1283, 2015.

35. Gu X,Zhang Q, Du Q, Shen H and Zhu Z: Pinocembrin attenuates allergic airway inflammation via inhibition of $N F-\kappa B$ pathway in mice. Int Immunopharmacol 53: 90-95, 2017.

36. Burke JR, Pattoli MA, Gregor KR, Brassil PJ, MacMaster JF McIntyre KW, Yang X, Iotzova VS, Clarke W, Strnad J, et al: BMS-345541 is a highly selective inhibitor of I kappa B kinase that binds at an allosteric site of the enzyme and blocks NF-kappa B-dependent transcription in mice. J Biol Chem 278: 1450-1456, 2003

37. MacMaster JF, Dambach DM, Lee DB, Berry KK, Qiu Y,Zusi FC and Burke JR: An inhibitor of IkappaB kinase, BMS-345541, blocks endothelial cell adhesion molecule expression and reduces the severity of dextran sulfate sodium-induced colitis in mice. Inflamm Res 52: 508-511, 2003.

38. Carneiro PJ, Clevelario AL, Padilha GA, Silva JD, Kitoko JZ, Olsen PC, Capelozzi VL, Rocco PR and Cruz FF: Bosutinib therapy ameliorates lung inflammation and fibrosis in experimental silicosis. Front Physiol 8: 159, 2017.

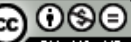

This work is licensed under a Creative Commons Attribution-NonCommercial-NoDerivatives 4.0 International (CC BY-NC-ND 4.0) License. 